\title{
IMPLANTAÇÃO DE CLASSE HOSPITALAR EM UM HOSPITAL PÚBLICO UNIVERSITÁRIO DE SÃO PAULO
}

\author{
HOSPITAL GRADE DEPLOYMENT IN A PUBLIC HOSPITAL \\ UNIVERSITY OF SÃO PAULO
}

\author{
Léa Chuster Albertoni ${ }^{1}$ \\ Barbara Niegia Garcia de Goulart ${ }^{2}$ \\ Brasilia Maria Chiari $^{3}$
}

Albertoni LC; Goulart BNG; Chiari BM. Implantação de classe hospitalar em um hospital público universitário de São Paulo. Rev Bras Cresc e Desenv Hum 2011; 21(2): 362-367.

\section{RESUMO}

Objetivo: descrever a implantação de classe hospitalar em hospital público universitário na cidade de São Paulo. Método: trata-se de descrever o processo, no período compreendido entre 2007 e o primeiro trimestre de 2011, nas respectivas etapas de implantação. Resultados: verificamos através de relatos dos familiares, profissionais da saúde e das escolas de origem dos alunos que a implantação da classe hospitalar colaborou na atenção às necessidades educacionais dos aluno e na inclusão destes na escola regular. Nota-se a importância da celebração dos convênios com as Secretarias da Educação do Estado e do Município e de novas medidas humanizadoras pós-implantação da classe hospitalar. Conclusão: a hospitalização pode significar uma experiência difícil para o paciente e sua família, porém a implantação da classe hospitalar principalmente em hospitais públicos representa um recurso potencial no desenvolvimento biopsicossocial da criança e do adolescente, colaborando na diminuição dos índices de fracasso e evasão escolar e na inclusão escolar dos alunos após a alta hospitalar.

Palavras-chave: criança hospitalizada; adolescente hospitalizado; evasão escolar; educação especial.

1 Psicopedagoga, Mestra, Coordenadora do Programa Classe Hospitalar do Departamento de Pediatria da Universidade Federal de São Paulo (UNIFESP)

2 Fonoaudióloga, Doutora e Pós-Doutoranda em Ciências [Fonoaudiologia] pela Universidade Federal de São Paulo (UNIFESP). Professora Adjunto da Universidade Federal do Rio Grande do Sul (UFRGS).

3 Fonoaudióloga, Professora Titular do Departamento de Fonoaudiologia da Universidade Federal de São Paulo (UNIFESP) Instituição na qual o trabalho foi realizado: Universidade Federal de São Paulo. Departamento de Fonoaudiologia. Programa de Pós-Graduação em Distúrbios de Comunicação Humana. Linha de Pesquisa: Comunicação Humana, Políticas Públicas e Inclusão. Correspondência para: Léa Chuster Albertoni - Unidade de Internaçao Pediátrica do Hospital São Paulo, Classe Hospitalar. Departamento de Pediatria: Rua Napoleão de Barros 715, $9^{\circ}$ andar. E- mail : albertonilc@uol.com.br - Fax: (11) 50493483 Tel. (11) 55391097 


\begin{abstract}
Objective: the goal of this article is to describe the hospital grade deployment in a university hospital in the city of São Paulo. Method: we described the process between 2007 and 2010, in their respective deployment steps. Results and discussion: we verified through reports and actions that the deployment of class hospital collaborated for continued training of teachers, construction of a systematic practice, meet the needs of students and their preparation for inclusion in regular school, integration of pedagogue in multidisciplinary team. We noted the importance of the conclusion of agreements with the secretariats of State education and of Town and new post-implementation hospital measures. Conclusion: hospitalization can mean a difficult experience for the patient and his/her family. The hospital grade deployment on a public university hospital represents a resource potential in the bio psychosocial development of children and adolescents, reducing the incidence of failure and dropout, and the inclusion of students after discharge.
\end{abstract}

Key words: hospitalized adolescent; hospitalized child; student dropouts; special education.

\section{INTRODUÇÃO}

O hospital, para a criança e para o adolescente internado, representa um ambiente desconhecido, restrito das possibilidades do seu cotidiano como brincar, conviver com amigos e familiares. O tema hospitalização tem despertado especial interesse entre os profissionais da saúde e da educação, quando se trata de analisar e intervir nos possíveis efeitos desta sobre o processo do desenvolvimento e da aprendizagem adoecimento ${ }^{1}$.

Bordin e Correa ${ }^{2}$ argumentam que a doença, como qualquer situação de crise, altera a vida do paciente pediátrico e sua família. A hospitalização pode conduzir tanto a um amadurecimento a um maior desenvolvimento psíquico, como resultar em prejuízo para o desenvolvimento físico e mental da criança e do adolescente hospitalizado, dado o volume de informações a que estão expostos. Segundo Fontes, este acervo precisa ser trabalhado pedagogicamente num contexto de atividades socializadas, que incluam também conteúdos escolares, informais e hospitalares ${ }^{3}$. Numa perspectiva mais recente, tem-se enfatizado a dimensão educativa como potencializadora do desenvolvimento em situações de crise ao apontar situações de aprendizagens significativas referentes à situação de adoecimento 4 .

A literatura sobre a relação do atendimento pedagógico-educacional no contexto hospitalar não é vasta, mas aponta para o importante papel do professor e desta modalidade educacional no resgate da saúde da criança hospitalizada ${ }^{1}$.

Ao operar com processos de conhecimentos afetivos e cognitivos, a educação traz a sua contribuição no resgate da saúde da criança hospitalizada. O trabalho pedagógico nos hospitais apresenta diversas interfaces de atuação sendo preciso compreender que educação não é um elemento exclusivo da escola, assim como a saúde não é um elemento exclusivo do hospital ${ }^{3}$. Reforça essa idéia a definição do Ministério da Saúde, segundo a qual,o hospital é parte integrante de uma organização médica e social, cuja função básica consiste em proporcionar à população assistência médica integral, curativa e preventiva, inclusive domiciliar, constituindose também em centro de educação, capacitação e de pesquisas em saúde ${ }^{5}$.

O tema implantação de classe hospitalar em uma instituição hospitalar pública e universitária, é de significativa importância, pois presta atendimento a uma população que tem 
na educação sua principal via de cidadania e esperança de ascensão social. Assim, as ações educativas na classe hospitalar, surgiram como elemento integrador entre as áreas da educação e da saúde, possibilitando às crianças e jovens hospitalizados o que a lei garante: o direito a educação.

Desta maneira, o objetivo é descrever o estado da arte na implantação de classe hospitalar.

\section{MÉTODO}

Relato de experiência que trata de descrever o processo de implantação da classe hospitalar em um hospital publico universitário na cidade de São Paulo, de base terciária e quaternária de alta complexidade. No período compreendido entre 2007 e o primeiro trimestre de 2011, abordaremos o processo segundo as respectivas etapas de implantação citadas a seguir:

\section{ELABORAÇÃO DO PROJETO E PROMOÇÃO DE CONVÊNIOS DE COOPERAÇÃO}

Nas Unidades de Internação Pediátricas (Clínica e Semi-intensiva Cirúrgica, DIPe-Disciplina de Infectologia Pediátrica, Casa de Apoio dos Pais Participantes), crianças e jovens de zero a 17 anos são internados com as mais diversas patologias, muitos deles em estado grave e com um histórico de longos períodos de internação, seguidos de reinternações.

No ano de 2007, com o objetivo de acrescentar atividades de cunho pedagógico-educacional à rotina de crianças e jovens hospitalizados, a chefia do Departamento de Pediatria, com o apoio da Diretoria do Hospital solicitou a uma pedagoga da universidade que dirigia uma escola para filhos de funcionários, a elaboração de um projeto pedagógico para implantar uma classe hospitalar. O projeto deveria contemplar os pressupostos legais e promover convênios de cooperação com as Secretarias da Educação do Estado e do Município.

Reconhecendo a importância do desenvolvimento biopsicossocial de crianças e adolescentes em situação de hospitalização, os Direitos Nacionais para Educação Especial na Educação Básica, por meio da Resolução n.41/ 95, do Conselho Nacional dos Direitos da Criança e do Adolescente, garantem para esta parcela da população, "o direito de desfrutar de alguma forma de recreação, programas de educação para a saúde e acompanhamento do currículo escolar, durante a sua permanência hospitalar" ${ }^{6}$. O suporte legal que institui normas para a educação de alunos com necessidades especiais em todas as suas etapas e modalidades e refere-se à classe hospitalar como "destinada a prover, mediante atendimento especializado, a educação de alunos impossibilitados de frequentar as aulas em razão de tratamento de saúde que implique na internação hospitalar ou atendimento ambulatorial"7. Também o Ministério da Educação (MEC), por meio da Secretaria de Educação Especial com o objetivo de estruturar as ações políticas de organização do sistema de atendimento educacional em ambientes hospitalares e domiciliares, estabelece estratégias e orientações para o funcionamento da classe hospitalar e do atendimento pedagógico domiciliar, através de um documento específico para este fim ${ }^{8}$. Este determina que às classes hospitalares e ao atendimento pedagógico domiciliar cabe garantir a manutenção do vínculo com as escolas por meio de um currículo flexibilizado e/ou adaptado, favorecendo seu ingresso, retorno ou integração ao seu grupo escolar correspondente, como parte do direito de atenção integral.

Assim sedimentados, os objetivos gerais do projeto-base se traduziram em colaborar na recuperação da saúde e, para minimizar os efeitos traumáticos da hospitalização, promover a inclusão social e educacional do aluno, analisar as possíveis dificuldades de aprendizagem bem como oferecer atividades de ação preven- 
tiva contra o fracasso e a evasão escolar. Constaram também da programação, oficinas temáticas com a participação de familiares e acompanhantes a fim de compartilhar as situações de aprendizagem no contexto hospitalar. Com o objetivo de promover a formação continuada da equipe pedagógica e aprimorar cada vez mais a prática do profissional da classe hospitalar, foi previsto um programa de capacitação que envolveu a participação de profissionais da saúde e da educação como médicos, enfermeiros, fisioterapeutas e nutricionistas, assistentes sociais e pedagogos docentes. $\mathrm{O}$ projeto foi aprovado e constituiu a base para o estabelecimento de dois convênios de cooperação com ambas as Secretarias do Estado e do Município.

\section{TRABALHO VOLUNTÁRIO}

Entre os anos de 2008 e meados de 2009, sem possibilidades de contratação de professores, sem a vinda dos professores conveniados e sem espaço físico circunscrito, o inicio dos trabalhos na classe hospitalar deu-se por intermédio do trabalho de pedagogos voluntários, com formação em Pedagogia Educação Física e Artes Cênicas. Para tanto, criou-se o Projeto Com...Vida segundo o qual, professores/voluntários frequentavam um programa de capacitação constituído por palestras elucidativas, ministradas por profissionais especializados nas respectivas áreas. Os temas abordados foram: aspectos do desenvolvimento, doenças crônicas, procedimentos e práticas da enfermagem, condutas médicas, comunicação e hospitalização, comunicação e biblioteconomia na hospitalização, distúrbios da comunicação e educação inclusiva. A coordenação do projeto também se preocupou em oferecer quinzenalmente ou quando a equipe sentisse necessidade, encontros com os profissionais da Saúde Mental do hospital e supervisões na área da Pedagogia e Psicopedagogia, com a finalidade de oferecer o suporte necessário aos atendimentos. Mesmo com muitas limitações, esse foi um período bastante proveitoso na construção do trabalho que hoje realizamos.

O Programa Classe Hospitalar sofreu importantes transformações desde seu início. Em 2009, a vinda de uma professora efetiva, cedida temporariamente por um colégio federal, garantiu a regularidade desse profissional em sala e, consequentemente, maior estabilidade ao trabalho. Em 2010, a Secretaria da Educação do Estado disponibilizou duas professoras contratadas também com frequência regular. Isso permitiu aumentar o número de atendimentos e oferecer maior flexibilidade de horário aos alunos. Outro fator importante foi a concessão de um espaço físico permanente e circunscrito, destinado à classe hospitalar, possibilitando atendimentos nas condições demandadas pelo aluno, ou seja, em sala de aula ou nos leitos.

\section{RESULTADOS E DISCUSSÃO}

A participação dos professores no programa de capacitação foi essencial para a atuação dos professores em cada etapa da implementação do projeto, uma vez que para atender as reivindicações dos alunos internados, são necessários conhecimentos específicos sobre a sua rotina, medicação e enfermidades, aspectos estes não inseridos na formação universitária do pedagogo. Nossas observações confirmam a bibliografia consultada ao referir-se que embora a grande maioria dos professores que atuam nos hospitais tenha nível de pós-graduação, a formação em serviço é a que tem assegurado uma condição de qualidade crescente no atendimento pedagógico $^{3,9,10}$.

Constatou-se também, a importância em estabelecer uma que contemplasse as necessidades dos alunos, mas que também considerasse a formulação de diretrizes curriculares e metodológicas, que garantam aos alunos o direito de inclusão na escola regular pós-hospitalização9. 
Para tanto, torna-se necessário analisar as possíveis dificuldades de aprendizagem, bem como, oferecer atividades de ação preventiva contra o fracasso e a evasão escolar 9 .

Para tanto, a equipe pedagógica em 2011, elaborou o Plano Político Pedagógico para classe hospitalar, assim como, um sistema de Verificação Contínua da Aprendizagem - VECAP. Segundo Teixeira de Paula ${ }^{10}$, é importante relacionar o tempo de hospitalização com a elaboração de uma programação individualizada direcionada às necessidades de cada criança e jovem hospitalizado ${ }^{10}$. Observou-se movimentos de aproximação para o trsbslho integrado construído pelas equipes de educação e saúde no sentido de suprir vo conhecimento sobre patologias e dados como por exemplo, previsões de alta.

Os convênios celebrados com as Secretarias da Educação do Estado e do Município oferecem suporte importante no funcionamento da classe hospitalar como provedores no envio de professores, de material didático e pedagógico. Citamos aqui os termos da Lei 9394/96-LDB que determinam como dever do Estado para com a educação escolar pública, a efetivação dos direitos de desfrutar de atendimento educacional especializado gratuito aos educandos com necessidades especiais.

Nota-se também a existência de outras medidas humanizadoras que aconteceram a partir da implantação da classe hospitalar, como integração de pais, professores a alunos, e a presença de profissionais do tipo atores "clow" (voluntários que adotam a "arte do palhaço" em atividades recreativas nos ambientes hospitalares) sugerindo formas criativas e funcionais de explorarem as rotinas hospitalares ${ }^{11}$.

Por fim, conclui-se que experiência de implantação da classe hospitalar surgiu como resposta ao reconhecimento de que a criança doente e hospitalizada,independente do período de permanência no hospital, da natureza de sua enfermidade, tem direito à escolarização, direito este que lhe é concedido pela Constituição Brasileira e pelas leis que são especificamente dedicadas à criança em situação de hospitalização ${ }^{6,13}$.

Também a implantação do serviço pedagógico educacional, favoreceu o reconhecimento formal do direito à educação e à ampliação das condições favoráveis para o enfrentamento da doença. Aos pedagogos professores que dela participam, fica registrada a necessidade de frequentar o programa de capacitação, que reafirma a importância da formação para o trabalho multidisciplinar, com ênfase na nos saberes necessários uma prática qualificada.

Desta maneira, ao inserir a pedagogia no contexto hospitalar, promove-se o atendimento às necessidades da criança e do adolescente hospitalizado no equilíbrio entre a sua saúde física, mental, cognitiva e social, oferecendo a oportunidade de melhora da qualidade de vida, corroborando também na implantação holística e humanística na práxis dos profissionais da saúde. 


\section{REFERÊNCIAS}

1. Ceccim RB. Classe hospitalar: encontros da educação e da saúde no ambiente hospitalar. Pátio. 1999;3(10):41-4.

2. Bordin IA, Corrêa MC. Ansiedade da criança hospitalizada: ausência ou dificuldade na relaçäo equipe-paciente? Rev Paul Pediatr. 1990;8(29):67-70.

3. Fontes RS. A escuta pedagógica à criança hospitalizada: discutindo o papel da educação no hospital. Rev Bras Educ [Internet]. 2005 [citado 2011 Mar 28];29:119-38. Disponível em: http:// www.scielo.br/scielo.php? script=sci arttext\&pid=S 1413 24782005000200010\&nrm=iso.

4. Oliveira LD, Gabarra LM, Marcon C, Silva JL, Macchiaverni J. A brinquedoteca hospitalar como fator de promoção no desenvolvimento infantil: relato de experiência. Rev Bras Crescimento Desenvolv Hum [Internet]. 2009 [citado 2011 Mar 28];19(2):306-12. Disponível em: http://pepsic.bvs-psi.org.br/ scielo.php?script=sci_arttext\&pid=S010412822009000200011.

5. Ministério da Saúde (BR). Definições e normas das instituições e serviços de saúde. Diário Oficial da República Federativa do Brasil, Brasília (DF); 1977 Abr 5; Seção I, Parte 1:3929.

6. Conselho Nacional dos Direitos da Criança e do Adolescente. Resolução ${ }^{\circ}$ 41/1995 de 13 de outubro de 1995. Aprova em sua íntegra o texto oriundo da Sociedade Brasileira de Pediatria, relativo aos Direitos da Criança e do Adolescente hospitalizados. Diário Oficial da Republica Federativa do Brasil, Brasília (DF); 1995 Out 17; Seção 1:163/9-16320.

7. Ministério da Educação (BR), Conselho Nacional da Educação. Resolução CNE/ CBE, n. 2, de 11 de setembro de 2001. Diretrizes Nacionais para a Educação Especial na Educação Básica [Internet]. Diário Oficial da República Federativa do Brasil, Brasília (DF); 2001 Out 14 [citado
2011 Fev 2]; Seção 1E(177):39-40. Disponível em: http://portal.mec.gov.br/ arquivos/pdf/resolucao2.pdf.

8. Ministério da Educação (BR), Secretaria da Educação Especial. Classe hospitalar e atendimento pedagógico domiciliar: estratégias e orientações para sua implantação e implementação (versão preliminar). Brasília (DF): MEC; 2002.

9. Amaral DP, Pereira e Silva MT. Formação e prática pedagógica em classes hospitalares: respeitando a cidadania de crianças e jovens enfermos [Internet]. 2009 [citado 2011 Mar 31]. Disponível em: http://www.smec.salvador.ba.gov.br/site/ documentos/espaco-virtual/espacoeducacao-saude/classes-hospitalares/ WEBARTIGOSformacao\%20e \%20pratica\% 20 pedagogica $\% 20$ em $\% 20$ classes $\%$ 20hospitalares....pdf.

10. Teixeira de Paula EM. Crianças e professores em hospitais: aprendizes especiais na diversidade dos contextos hospitalares. Igualdade e diversidade na educação XI Endipe Encontro Nacional de Didática e Prática de Ensino; 2002 Maio 26-29; Goiânia, GO. 2002.

11. Araújo TC, Guimarães TB. Interações entre voluntários e usuários em oncohematologia pediátrica: um estudo sobre os palhaços-doutores. Est Pesqui Psicol [Internet]. 2009 [citado 2011 Abr 1]; 9(3): 632-47. Disponível em: http://pepsic.bvspsi.org.br/s c i e lo.ph p ? s c riptsci_arttext \& pid $=$ S1808-42812009000300006.

12. Senado Federal (BR). Constituição Federal de 5 de outubro de 1988. Brasília (DF): Senado Federal; 1988.

13. Ministério da Educação e do Desporto (BR), Secretaria da Educação Especial. Política nacional de educação especial. Livro 1. Brasília (DF): MEC-Seesp; 1994.

Recebido em: 08/ago./2010 Modificado em 26/nov./2010 Aceito em 16/mar./2011 